\title{
Relationship between in vitro gas production and dry matter and organic matter digestibility of rations for sheep
}

\author{
G.-Y. Zhao' ${ }^{1}$ Y. Xue and W. Zhang \\ State Key Laboratory of Animal Nutrition, College of Animal Science and Technology, \\ China Agricultural University \\ Beijing 100094, P.R. China
}

\begin{abstract}
Twelve typical mixed rations of sheep were formulated to study the relationship between in vitro gas production (GP) and in vivo nutrient digestibility (D). The in vitro GP of the rations at, h: 2, 4, $6,12,24,48$ and 72 was determined using the Hohenheim gas test. The in vivo digestibility of dry matter (DM), organic matter $(\mathrm{OM})$ was determined using three adult sheep in four $3 \times 3$ Latin square design experiment in an earlier study (Xue et al., 2006). The GP at different incubation time was fitted to the model $G P=a+b\left(1-e^{-c t}\right)$ (Ørskov and McDonald, 1979) and the GP parameters $a(\mathrm{ml} / 200$ $\mathrm{mg} \mathrm{DM}), b(\mathrm{ml} / 200 \mathrm{mg} \mathrm{DM}), a+b(\mathrm{ml} / 200 \mathrm{mg} \mathrm{DM})$ and $c(\% / \mathrm{h})$ were calculated. It was found that there were significant regression relationships between $\mathrm{DM}$ and $\mathrm{OM}$ digestibility and $\mathrm{GP}(\mathrm{P}<0.001)$, and between DM and OM digestibility and GP parameters $a, b$ and $c(\mathrm{P}<0.01 ; \mathrm{P}<0.001)$.
\end{abstract}

KEY WORDS: in vitro, gas production, nutrient digestibility, sheep

\section{INTRODUCTION}

Accurate prediction of nutrient digestibility of sheep using easier technique is important because it saves a lot of work. The gas production (GP) of feedstuffs may be the best indicator of the rumen apparent digestibility of feedstuffs (Blümmel and Ørskov, 1993) and in vitro GP of feedstuffs was well correlated to in vivo OM digestibility in sheep (Menke et al., 1979). The in vitro GP parameters $a, b, c$ of the model GP $=a+b\left(1-\mathrm{e}^{-\mathrm{ct}}\right)$ (Ørskov and McDonald, 1979) was also correlated to in vivo DM digestibility of single feedstuffs in sheep (Khazaal et al., 1993; 1995). The in vitro GP was therefore used for the evaluation of nutritive value of

\footnotetext{
${ }^{1}$ Corresponding author: e-mail: zhaogy@cau.edu.cn
} 
feedstuffs or for the prediction of in vivo nutrient digestibility (De Boever et al., 2005). Normally sheep are fed with mixed rations that contain different feedstuffs instead of single feedstuffs. The objective of the experiments was to study the relationship between the in vitro GP and the in vivo digestibility of DM and OM of 12 typical mixed rations of sheep, and also study the possibility of predicting in vivo nutrient digestibility from in vitro GP or GP parameters.

\section{MATERIAL AND METHODS}

\section{Determination of nutrient digestibility}

Twelve typical rations for sheep were combined as experimental samples which were the same as those of Li and Zhao (2007). The nutrient digestibility of the mixed rations was determined in an early experiment (Xue et al., 2006).

\section{In vitro GP measurement}

The mixed rations were milled through a $2.5 \mathrm{~mm}$ sieve for the determination of in vitro GP. Three adult male sheep (Small Tailed Han sheep $\times$ Dorset sheep, average body weight $58.7 \mathrm{~kg}$ ), each fitted with a rumen cannula, were used as the donors of rumen fluid. Each animal was fed with $1400 \mathrm{~g}$ of a mixed ration daily. The ration contained, $\%$ : wild rye 70 , maize 20 , soyabean meal 4.6 , cottonseed meal 2.5, wheat bran 2 and minerals 0.9 , in two equal meals at 8.00 and 17.00, respectively, and the animals had free access to drinking water.

The GP was determined using the in vitro incubation technique of Menke et al. (1979).

\section{Chemical analysis}

The DM of the samples was determined by drying in an oven at $105^{\circ} \mathrm{C}$ for 8 h. The $\mathrm{OM}$ was calculated as weight loss after ashing of feed samples at $550^{\circ} \mathrm{C}$ overnight. The $\mathrm{CP}$ was determined using the Kjeldahl method.

\section{Calculation}

The in vitro GP was calculated as: $G P=\left(V_{\text {final }}-V_{\text {initial }}-V_{\text {blank }}\right) / 200 \mathrm{mg} \mathrm{DM}$, where: $G P$ refers to gas production, $\mathrm{ml} / 200 \mathrm{mg} \mathrm{DM} ; V_{\text {initial }}$ gas volume before incubation started, ml; $V_{\text {final }}$, gas volume at the end of incubation, $\mathrm{ml} ; V_{\text {blank }}$, gas volume produced in blank, $\mathrm{ml}$. 
The in vitro GP of the rations was fitted to the model $G P=a+b\left(1-e^{-c t}\right)$ (Ørskov and McDonald, 1979) and the parameters $a, b$ and $c$ were calculated, where: GP refers to gas production, $\mathrm{ml} / 200 \mathrm{mg} \mathrm{DM} ; t$, incubation time, $\mathrm{h} ; a$, gas production from the immediately fermentable fraction, $\mathrm{ml} / 200 \mathrm{mg} \mathrm{DM} ; b$, gas production from the slowly fermentable fraction, $\mathrm{ml} / 200 \mathrm{mg} \mathrm{DM} ; c$, gas production rate of fraction $b, \% / \mathrm{h}$.

\section{Statistical analysis}

The relationship between nutrient digestibility and GP or GP parameters $a, b$, $c$, and the data was analysed using SPSS 10.0 based on the following models:

$$
\begin{aligned}
& D=B(G P)+A \\
& D=B_{1}(a)+B_{2}(b)+A \\
& D=B_{(}(a+b)+A \\
& D=B_{1}(a+b)+B_{2}(c)+A \\
& D=B_{1}(a)+B_{2}(b)+B_{3}(c)+A
\end{aligned}
$$

where: $D$ refers to apparent nutrient digestibility, $\% \mathrm{DM} ; G P$, in vitro gas production at different time points, $\mathrm{ml} / 200 \mathrm{mg} \mathrm{DM} ; a, b$ and $c$, gas production parameters in the model $G P=a+b\left(1-e^{-c t}\right) ; A, B, B_{1}, B_{2}$ and $B_{3}$, constants in Models I, II, III, IV and $\mathrm{V}$.

\section{RESULTS}

The digestibility of DM and OM of the rations was shown in Table 1 . The digestibility (\%DM) of DM and OM and the cumulative GP ( $\mathrm{ml} / 200 \mathrm{mg} \mathrm{DM})$ of the rations at, h: $6,12,24,48$ or 72 was fitted to Model I, and the equations, regression coefficients and $\mathrm{P}$ value were shown in Table 2.

It could be found that the relationship between DM and OM digestibility and GP of all different time points was highly significant $(\mathrm{P}<0.001)$. However, the regression coefficients $\left(\mathrm{r}^{2}\right)$ varied depending on incubation time and different nutrients. The regression coefficient $\left(\mathrm{r}^{2}\right)$ between DM digestibility and $12 \mathrm{~h}$ GP was 0.737 , which was the highest.

The GP parameters $a, b$ and $c$ of the rations were calculated and listed in Table 3. Using Model II-V, the relationship between nutrient digestibility and GP parameters $a, b$ and $c$ was statistically analysed and the equations are shown in Table 4. It could be found that the relationship between DM and OM digestibility and GP parameters was significant $(\mathrm{P}<0.01)$ or highly significant $(\mathrm{P}<0.001)$. 

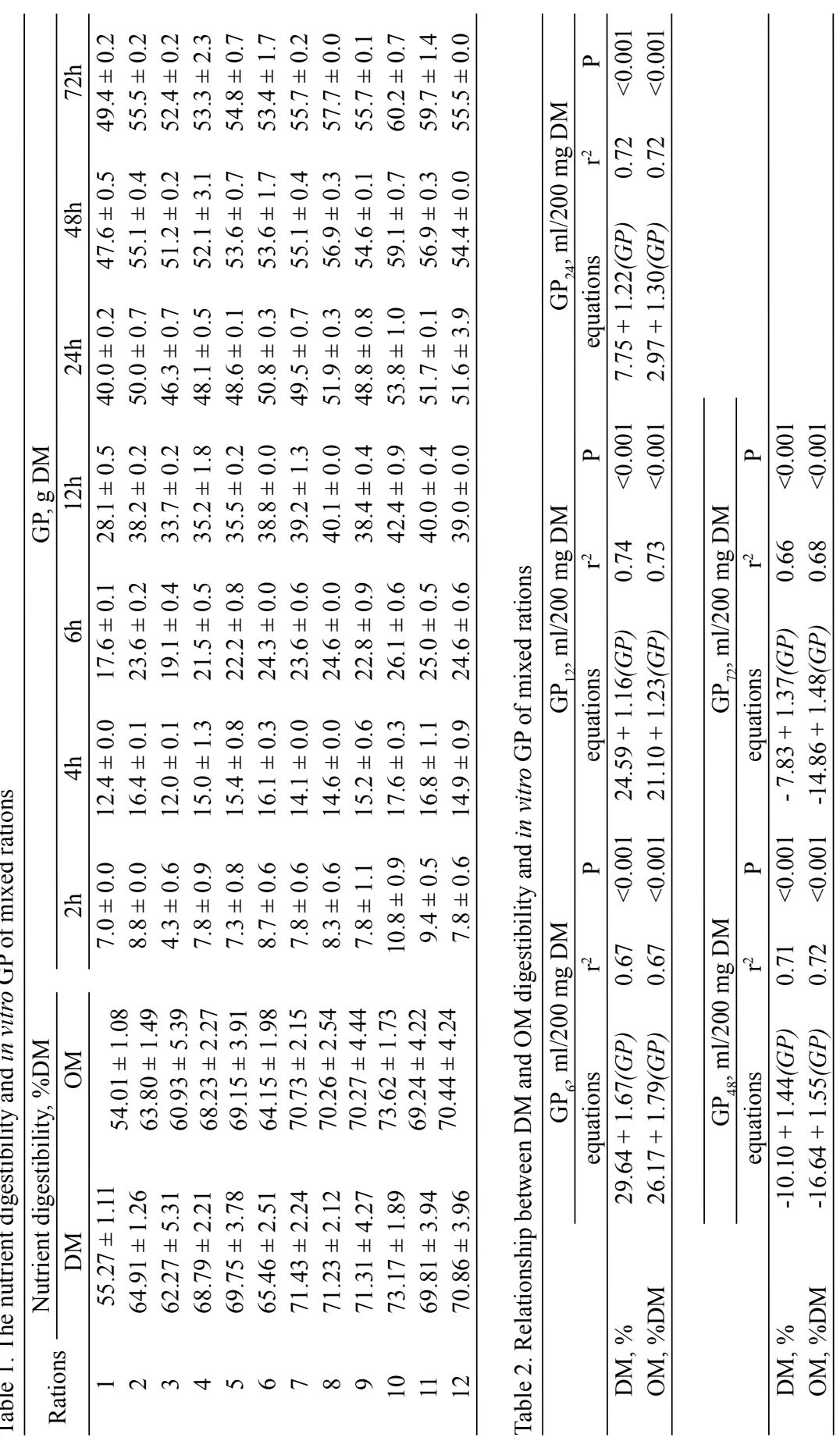
Table 3. The fitted in vitro GP parameters ${ }^{1}$

\begin{tabular}{ccccrc}
\hline Rations & $a$ & $b$ & $(a+b)$ & $c(\% / \mathrm{h})$ & RSD \\
\hline 1 & 1.68 & 47.84 & 49.52 & 6.53 & 0.78 \\
2 & -0.75 & 55.76 & 55.01 & 9.75 & 1.49 \\
3 & -4.75 & 56.14 & 51.39 & 9.44 & 1.95 \\
4 & -1.07 & 54.24 & 53.17 & 9.43 & 2.05 \\
5 & -0.60 & 54.58 & 53.98 & 8.95 & 1.75 \\
6 & -1.70 & 55.10 & 53.40 & 10.59 & 1.77 \\
7 & -5.49 & 60.35 & 54.86 & 11.10 & 1.42 \\
8 & -4.40 & 60.76 & 56.36 & 10.76 & 1.49 \\
9 & -2.59 & 57.19 & 54.60 & 9.88 & 0.98 \\
10 & -0.71 & 59.68 & 58.97 & 10.09 & 1.27 \\
11 & -0.91 & 58.82 & 57.91 & 9.59 & 1.09 \\
12 & -4.45 & 59.01 & 54.56 & 10.95 & 1.16 \\
\hline
\end{tabular}

${ }^{1}$ fitted to model $G P=a+b\left(1-e^{-c t}\right)$ (Ørskov and McDonald, 1979)

the unit of $a, b$ and $a+b$ is $\mathrm{ml} / 200 \mathrm{mg} \mathrm{DM}$

Table 4. Relationship between DM and OM digestibility and GP parameters

\begin{tabular}{cllc}
\hline Digestibility, \% & \multicolumn{1}{c}{ Equations } & $\mathrm{r}^{2}$ & $\mathrm{P}$ \\
\hline $\mathrm{DM}$ & $0.74 a+1.52 b-16.67$ & 0.769 & $<0.001$ \\
$\mathrm{OM}$ & $0.92 a+1.66 b-25.07$ & 0.768 & $<0.001$ \\
$\mathrm{DM}$ & $1.61(a+b)-19.58$ & 0.660 & $<0.001$ \\
$\mathrm{OM}$ & $1.74(a+b)-27.84$ & 0.682 & $<0.001$ \\
& & & \\
$\mathrm{DM}$ & $1.10(a+b)+1.83(c)-9.73$ & 0.785 & $<0.001$ \\
OM & $1.26(a+b)+1.73(c)-18.51$ & 0.780 & $<0.001$ \\
$\mathrm{DM}$ & $0.94(a)+1.20(b)+1.35(c)-11.34$ & 0.789 & $<0.01$ \\
$\mathrm{OM}$ & $1.11(a)+1.36(b)+1.26(c)-20.09$ & 0.783 & $<0.01$ \\
\hline
\end{tabular}

$a(\mathrm{ml} / 200 \mathrm{mg} \mathrm{DM}), b(\mathrm{ml} / 200 \mathrm{mg} \mathrm{DM})$ and $c(\% / \mathrm{h})$

\section{DISCUSSION}

From Table 1, it could be found that the GP of the rations increased with incubation time. Therefore the GP of any single time point could not completely reflect the GP characteristics of the rations. In Model I, only one GP value of a certain time point was used, therefore, Model I might not completely represent the variation of GP at different incubation time.

Comparing different models, the regression coefficients $\left(\mathrm{r}^{2}\right)$ of $\mathrm{DM}$ and $\mathrm{OM}$ in Model V were the highest, followed by Model IV and Model II. The results indicated that Model V would be the best to represent GP characteristics of mixed rations and could be used for the prediction of nutrient digestibility. 


\section{CONCLUSIONS}

It was concluded that the apparent digestibility of DM and OM of the typical mixed rations of sheep were significantly correlated to gas production (GP) and GP parameters $a, b$ and $c$. The apparent digestibility of DM and OM could be predicted based on in vitro GP parameters $a, b$ and $c$.

\section{REFERENCES}

Blümmel M., Ørskov E.R., 1993. Comparison of gas production and nylon bag degradability of roughages in predicting feed intake in cattle. Anim. Feed Sci. Tech. 40, 109-119

De Boever J.L., Aerts J.M., Vanacker J.M., De Brabande D.L., 2005. Evaluation of the nutritive value of maize silages using a gas production technique. Anim. Feed Sci. Tech. 123-124, $255-$ 265

Khazaal K., Dentinho M.T., Ribeiro J.M., Ørskov E.R., 1993. A comparison of gas production during incubation with rumen contents in vitro and nylon bag degradability as predictors of the apparent digestibility in vivo and the voluntary intake of hays. Anim. Prod. 57, 105-112

Khazaal K., Dentinho M.T., Ribeiro J.M., Ørskov E.R., 1995. Prediction of apparent digestibility and voluntary intake of hays fed to sheep: comparison between using fibre components, in vitro digestibility or characteristics of gas production or nylon bag degradation. Anim. Sci. 61, 527538

Li Y.X., Zhao G.Y., 2007. Prediction of utilizable true protein of mixed rations for sheep using an in vitro incubation technique. Arch. Anim. Nutr. 61, 203-213

Menke K.H., Raab L., Salewski A., Steingass H., Fritz D., Schneider W., 1979. The estimation of the digestibility and metabolizable energy content of ruminant feedingstuffs from the gas production when they are incubated with rumen liquor in vitro. J. Agr. Sci. 93, 217-222

Ørskov E.R., McDonald I., 1979. The estimation of protein degradability in the rumen from incubation measurements weighted according to rate of passage. J. Agr. Sci. 92, 499-503

Xue Y., Li Y.X., Ren J.B., Zhao G.Y., 2006. Studies on the digestibility of low protein rations of sheep. Chinese J. Anim. Sci. 42 (19), 46-48 